OPEN

SUBJECT AREAS:

ECOLOGICAL

MODELLING

AGRI-ECOLOGY

Received

6 November 2013

Accepted

28 February 2014

Published

20 March 2014

Correspondence and requests for materials should be addressed to

L.H. (laure.hossard@ supagro.inra.fr)

\section{Effects of halving pesticide use on wheat production}

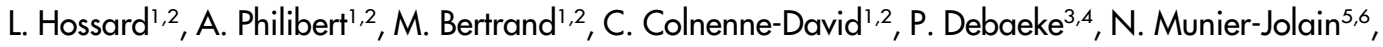 \\ M. H. Jeuffroy ${ }^{1,2}$, G. Richard7 \& D. Makowski ${ }^{1,2}$
}

${ }^{1}$ INRA, UMR2 11 Agronomie, F-78850 Thiverval-Grignon, France, ${ }^{2}$ AgroParisTech, UMR Agronomie, F-78850 Thiverval-Grignon, France, ${ }^{3}$ INRA, UMR 1248 AGIR, F-31320 Castanet-Tolosan, France, ${ }^{4}$ Université de Toulouse, INPT, UMR AGIR, F-31029 Toulouse, France, ${ }^{5}$ INRA, UMR 1347 Agroecologie, F-2 1065 Dijon, France, ${ }^{6}$ AgroSup Dijon, UMR Agroecologie, F-2 1065 Dijon, France, ${ }^{7}$ INRA, UAR 1155 Département Environnement et Agronomie, F-84914 Avignon, France.

Pesticides pose serious threats to both human health and the environment. In Europe, farmers are encouraged to reduce their use, and in France a recent environmental policy fixed a target of halving the pesticide use by 2018. Organic and integrated cropping systems have been proposed as possible solutions for reducing pesticide use, but the effect of reducing pesticide use on crop yield remains unclear. Here we use a set of cropping system experiments to quantify the yield losses resulting from a reduction of pesticide use for winter wheat in France. Our estimated yield losses resulting from a 50\% reduction in pesticide use ranged from 5 to $13 \%$ of the yield obtained with the current pesticide use. At the scale of the whole country, these losses would decrease the French wheat production by about 2 to 3 millions of tons, which represent about $15 \%$ of the French wheat export.

T he average yield of cereal crops increased by more than $98 \%$ worldwide, and by more than $187 \%$ in France from 1960 to $1990^{1}$ and part of this dramatic yield increase is due to the increasing use of pesticides. However, farmers and agricultural scientists have now to deal with a paradox: due to a rapidly-growing population and to the lack of availability of new farmland, it will be necessary to continue to increase crop yields in the future ${ }^{2}$. On the other hand, it is necessary to reduce the harmful effect of pesticides on human health and on the environment ${ }^{3}$. Several studies have shown that exposure to pesticides poses serious threats to human health of both professional (especially farmers) and rural populations $\mathrm{s}^{4,5}$ and that high levels of pesticide applications can harm water quality and biodiversity, especially in western Europe ${ }^{6}$. In France, $37 \%$ of mean pesticide concentrations in watercourse did not conform with the quality standard established by the European Water Framework Directive for drinking water $\left(0.5 \mu \mathrm{g} \mathrm{l^{-1 }}\right.$ for total pesticides $\left.{ }^{7}\right)$ in $2011^{8}$. In order to alleviate this problem, an environmental policy was adopted in 2008 in France aimed at reducing pesticide use by $50 \%$ by $2018^{9}$, but it remains unclear to what degree pesticide use reduction causes yield losses.

Organic and/or integrated cropping systems have been proposed to reduce pesticide use and pesticide exposure in areas where pesticide doses are high ${ }^{10,11}$. Organic systems aim to produce food with minimal impact on humans, animals and ecosystems, by using no synthetic inputs (mineral fertilizers, pesticides). Widespread adoption of these zero-pesticide systems in areas where pesticides are currently used at high levels will strongly decrease pesticide exposure, but it is also likely to result in high yield losses. Two recent meta-analyses showed that the substitution of conventional high-input systems with organic systems would lead to 19 to $34 \%$ of yield loss ${ }^{12,13}$, which could be disastrous in view of the current challenge of feeding 9 billion people by $2050^{14,15}$.

In integrated cropping systems, pesticides are used to control pests and diseases only when a risk of damage is established, and pesticide sprays are reduced as much as possible by using other cropping practices aiming at reducing the occurrence of pests and diseases (e.g. resistant cultivars, minimum tillage, lower nitrogen fertilizer rates) ${ }^{11,16}$. Potentially, these systems can lead to higher yields than organic systems and to lower pesticide use than conventional high-input cropping systems. They can thus represent an interesting compromise between organic and high-input cropping systems. For some crops, they may also be more profitable for farmers than high-input systems ${ }^{17}$. A great diversity of integrated systems exist, which include varying levels of pesticide use that may lead to different levels of yield loss compared to high-input conventional systems.

Here we use a set of cropping system experiments to quantify the yield losses resulting from a reduction in pesticide use for winter wheat in France. We chose to focus on winter wheat because wheat is the first crop grown in terms of acreage in France and in the world ${ }^{1}$. Our dataset includes 176 wheat yield measurements obtained in organic, integrated, and conventional systems in four different sites in France located in major wheat-producing 
areas (two sites in the Paris area, one in Toulouse, and one in Dijon; supplementary material S1). In these experiments, the level of pesticide use was described by a synthetic indicator: the Treatment Frequency Indicator (TFI). TFI is equal to the sum, for the various applications, of the ratio of the applied pesticide dose to the national recommended dose: $\mathrm{TFI}=\sum_{\mathrm{T}} \mathrm{AD}_{\mathrm{T}} / \mathrm{RD}_{\mathrm{T}}$, where $\mathrm{T}$ is the index of pesticide product, $\mathrm{AD}$ is the applied dose per hectare and $\mathrm{RD}$ is the recommended dose per hectare ${ }^{18,19}$. This indicator allows us to describe pesticide use through a single synthetic variable; it takes into account all the pesticide treatments applied in a given crop field (except for the seed treatments), and weights the applied pesticide doses according to the recommended doses in order to take the intensities of the pesticide treatments into account. TFI was calculated for the 176 wheat plots included in our dataset, and was related to wheat yields using several statistical models. The fitted models were then used to estimate the yield loss induced by different levels of pesticide use reduction.

Although the tested cropping system experiments were designed to generate limited yield losses compared to conventional systems, some of the wheat plots included in our dataset were affected by weeds, pests and diseases. Levels of disease and pest infestation have been measured in a few plots, but not systematically. Several plots in Dijon were infested by Alopecurus myosuroides, an important weed species, and the density of this species varied across cropping systems ${ }^{20}$. In the Versailles experiment, several plots were found infected by leaf $\operatorname{spot}^{21}$ and eyespot ${ }^{22}$ fungal diseases. Other factors may have also limited yield, such as nutrient and water deficits, high temperature effects, or frost damage. Wheat limiting factors are potentially very numerous and difficult to select, and their effects are difficult to estimate accurately using classical regression ${ }^{23}$. In this study, we consider these limiting factors as unmeasured variables, but we did not assume that these factors were absent, and we tried to account for their potential effects when estimating the effect of pesticide use reduction. Several authors have pointed out that the estimated effects for the measured explanatory variable were not well represented by variation in the means and medians of response variable distributions, when there were other unmeasured factors that were potentially limiting ${ }^{24}$. This being so, there may be a weak relationship between the mean (or the median) of the response variable (here, yield) distribution and the measured explanatory variable (here, TFI), but there may be a stronger relationship with the other parts of the response variable distribution where the unmeasured limiting factors have small effects ${ }^{24}$. When the interaction between the measured and unmeasured explanatory variables is negative, changes near the maxima of the response distribution, rather at the centre of the response distribution, are better estimates of the effect of the measured explanatory variable. Conversely, when the interaction is positive, changes near the minima lead to better estimates ${ }^{25,26}$.

In this study, the central and the extreme parts of the yield data distribution were both investigated using two statistical methods, quantile regression $^{27}$ and stochastic frontier analysis ${ }^{28}$. Quantile regression was used here in order to explore different parts of the yield distribution corresponding to different quantiles. The stochastic frontier model allowed us to determine a function relating the maximum possible yield value that can be achieved for a given value of TFI. With both methods, two functional forms were considered successively for relating yield to TFI; a linear function relating logtransformed yield to log-transformed TFI (referred to as log function), and a quadratic function directly relating yield to TFI. The pesticide use reduction effect was estimated using the two statistical methods and the two functional forms in order to analyse the sensitivity of the results to the statistical model assumptions.

\section{Results}

Measured values of grain yield and TFI ranged from 2.1 to $10.1 \mathrm{tha}^{-1}$ and from 0 to 9.4 respectively (Figure 1). This range of TFI values includes the mean value of TFI, namely 4.1, reported for wheat in France in 2006 and derived from a national survey on crop management practices". This survey ("Enquête sur les Pratiques Culturales") was conducted to collect farming practices for 12,900 fields considered as representative of main field crop production in France; soft winter wheat represented about $27 \%$ of surveyed fields ${ }^{30}$ (see Supplementary material S1). As no survey has been published between 2006 and the onset of the environmental program $(2008)^{9}$, the TFI 4.1 value is used here as a reference describing the current pesticide use level for wheat in France. In France, the average wheat yield between 2008 and 2012 was 7.11 tons per hectare ${ }^{1}$. This value is close to the median yield value estimated in our study for this TFI.

The fitted yield response curves obtained are located in different parts of the yield data distribution depending on the quantile value (Figure 1). They are located in the centre of the yield data distribution when the quantile is set at 0.5 (median), and in the upper and lower parts of the yield data distribution when the quantile value is set to a higher or lower value respectively (Figure 1). Most of the fitted curves appear to be rather parallel, with some exceptions for the most extreme quantiles. The estimated parameter values were all significantly different from zero $(\mathrm{p}<0.01)$ with one exception; the parameter values of the quadratic function fitted for the $90 \%$ percentile. The shapes of the fitted responses of yield to TFI are different depending on the response functions (Figure 1). With the log function, grain yield is described as an increasing function of TFI for the whole range of TFI values (Figure 1A). On the other hand with the quadratic function (Figure 1B), yield increases as a function of TFI only when TFI is below a threshold falling between 6 and 8, depending on the quantile. Above this threshold, yield decreases as a function of TFI. The only exception is the quadratic response curve fitted for the quantile 0.9 ; this curve does not include any yield-decreasing part for the whole range of TFI values considered in this study.

The two yield response curves obtained using the stochastic frontier analysis method lie in the upper part of the yield data distribution (Figure 2). The estimated parameter values were all significantly different from zero $(p<0.01)$. Their shapes depend on the function considered and show an increasing trend with the log function, and an increasing and then decreasing trend with the quadratic function. The confidence interval is narrower with the log function than with the quadratic function (Figure 2). The level of uncertainty associated with the fitted yield response curve is thus higher when the quadratic function is used. The width of the confidence interval increases as a function of TFI, revealing higher uncertainty for high TFI values than for low ones (Figure 2). Wider confidence intervals were also obtained for high TFI values with the quantile regression method (Supplementary material S2).

Based on the results obtained using the quantile regression method and the log function, yield losses induced by a $50 \%$ reduction in pesticide use (from TFI $=4.1$ ) range from $0.39 \mathrm{t} \mathrm{ha}^{-1}$ to $0.59 \mathrm{t}$ $\mathrm{ha}^{-1}$, depending on the quantile value (Figure $3 \mathrm{~A}$ ). The estimated yield losses are higher with the quadratic function (Figure $3 \mathrm{~B}$ ); they range from $0.69 \mathrm{t} \mathrm{ha}^{-1}$ to $0.88 \mathrm{t} \mathrm{ha}^{-1}$, depending on the chosen quantile. With both functions, there is no clear relationship between the estimated yield loss and the quantile. The quadratic function and the lowest quantiles $(0.1)$ generate wider confidence intervals and, thus, more uncertain estimates (Figure 3, Table 1). According to the results of the stochastic frontier analysis method, the yield loss induced by a $50 \%$ pesticide use reduction is 0.47 and $0.83 \mathrm{tha}^{-1}$ with the $\log$ and quadratic function respectively (Table 1). With this method also, the confidence interval is wider with the quadratic function.

According to the results of the quantile regression method, zeropesticide systems, as compared to a TFI of 4.1, would generate a yield loss ranging from 1.91 to $2.57 \mathrm{t} \mathrm{ha}^{-1}$ based on the log function and from 1.33 to $2.33 \mathrm{t} \mathrm{ha}^{-1}$ based on the quadratic function (Figure 3). The confidence intervals associated with these estimates are wider 
A. $\log$ function

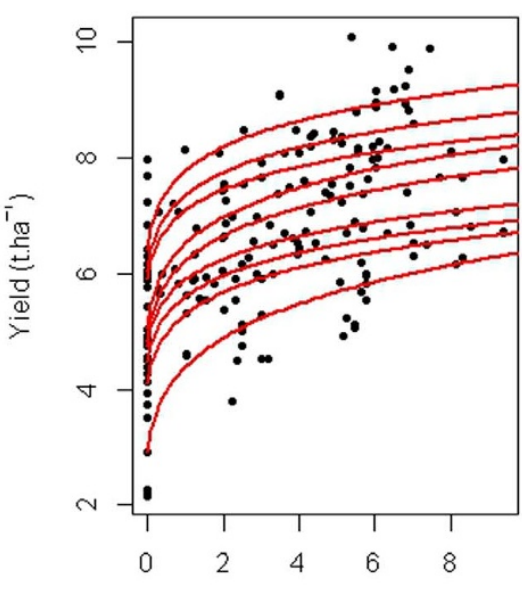

$\mathrm{TFI}$
B. Quadratic function

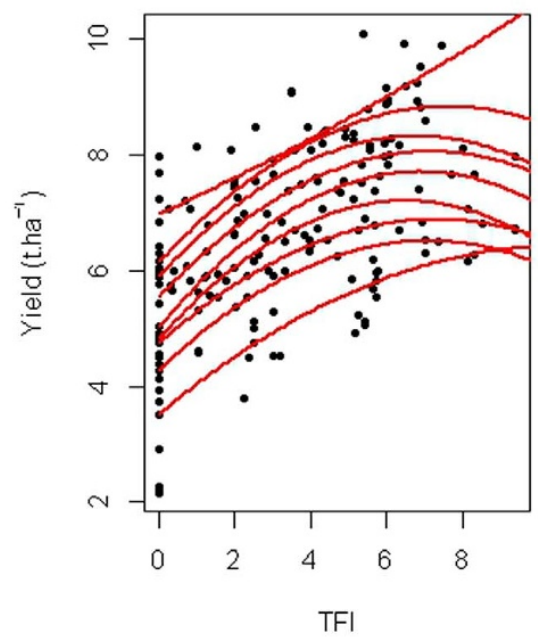

Figure $1 \mid$ Nine yield response curves fitted by quantile regression, for quantile values ranging from 0.1 (lowest curve) to 0.9 (highest curve) with a step of 0.1. Two different functions were considered; $\log (\mathrm{A})$ and quadratic (B). Black points indicate the yield data.

than those obtained for the yield loss estimates resulting from a $50 \%$ pesticide use reduction, especially for the two most extreme quantiles (0.1 and 0.9). If we exclude these two quantiles, yield loss associated with zero-pesticide cropping systems ranges from 1.73 to $2.43 \mathrm{tha}^{-1}$. According to the results of the stochastic frontier analysis method, the yield loss induced by zero-pesticide cropping system would be equal to $2.33 \mathrm{tha}^{-1}$ based on the $\log$ function and to $1.98 \mathrm{tha}^{-1}$ based on the quadratic function (Table 2).

\section{Discussion}

In our study, the effect of reducing pesticide use was assessed using a synthetic indicator, TFI. It is recognized that different pesticides have different impacts on yield, on farmers' costs, on the environment, and on human health ${ }^{5,31}$. Our indicator takes part of these differences into account through the use of the recommended doses. An advantage of this indicator is that it allows us to evaluate the consequence of an overall reduction of the level of pesticide use using a single response function. However, it did not allow us to determine whether specific pesticide types (e.g. herbicides, insecticides or fungicides) should be reduced in preference to others. As fungicides and herbicides contribute to about $77 \%$ of the TFI values of winter wheat ${ }^{32}$, a substantial reduction of these two pesticide types will be required to halve TFI values.

Estimated yield losses obtained with quantile regression and stochastic frontier analysis were similar. As the fitted curves are all almost parallel, values estimated by quantile regression were not very sensitive to the chosen quantile; the estimated effects of a TFI decrease on yield were similar for all quantiles of the yield data distribution. Based on the reasoning of previous studies ${ }^{25,26}$, this result is due to either a small interaction between TFI and the unmeasured factors, or an additive interaction in the situations considered in our dataset. The use of the quadratic function led to higher estimated losses with both statistical methods. Compared to the quadratic function, we found that the log function led to a less uncertain estimated yield loss, especially for high levels of pesticide use (Figure 1; Supplementary material S2). The shape of this function also appears more consistent with the results of previously published papers showing that a decrease in pesticide use tends to penalize yield and increase the risk of crop failure ${ }^{33,34}$. The yield-decreasing part predicted by the quadratic function for high values of TFI probably

\section{A. Log model}

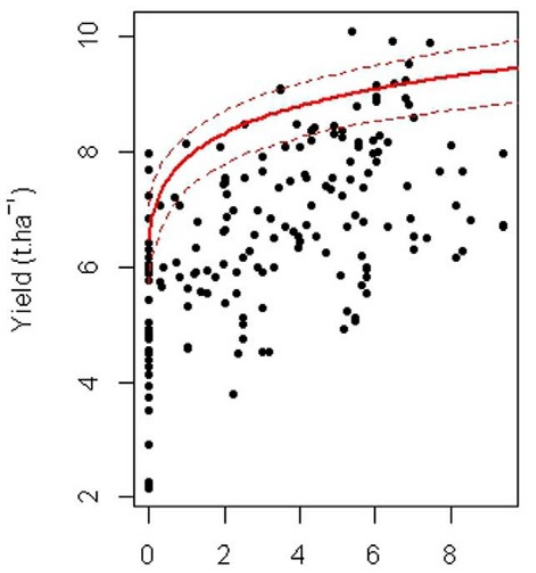

\section{B. Quadratic model}

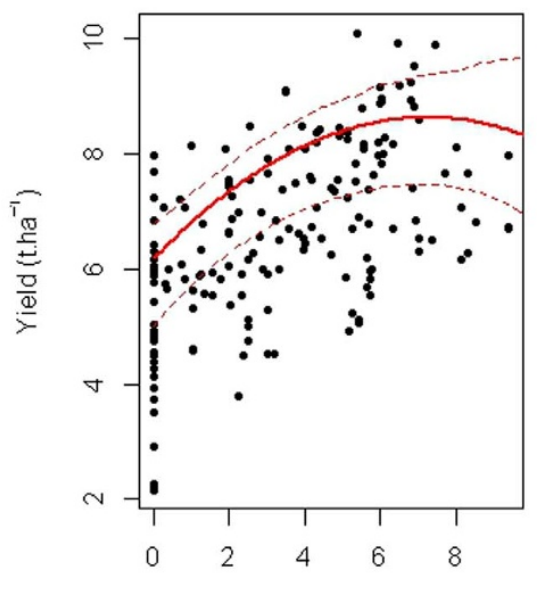

TFI

Figure $2 \mid$ Fitted yield response curves obtained with the stochastic frontier analysis method using the $\log$ function (A) and the quadratic function (B). Dotted lines indicate the $95 \%$ confidence intervals of the fitted curves. 
A. Log function

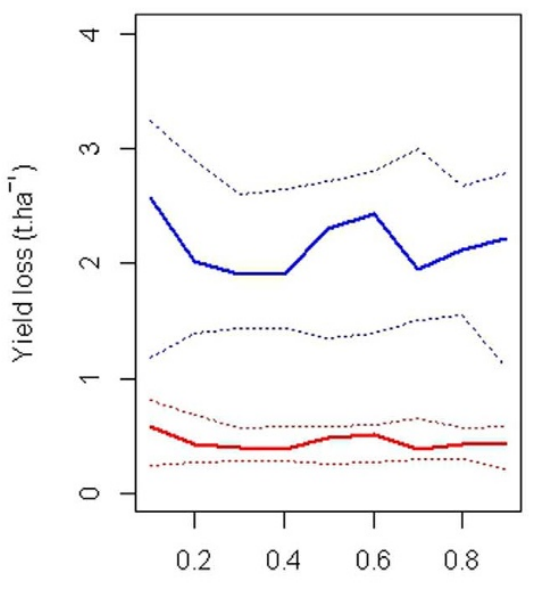

Quantile
B. Quadratic function

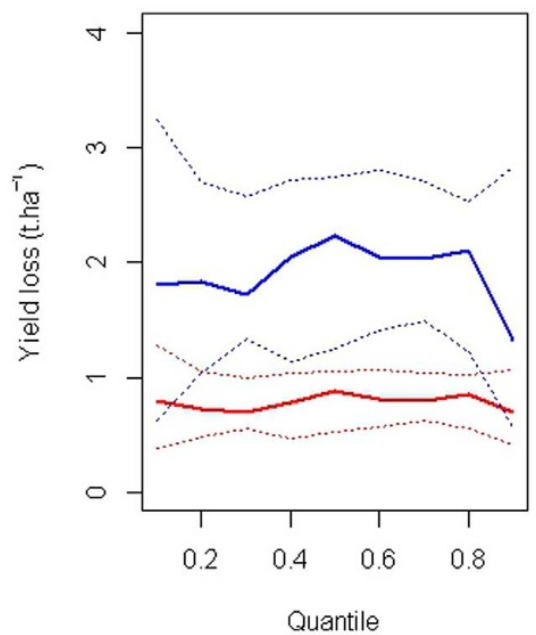

Figure 3 Y Yield losses resulting from a 50\% reduction of pesticide use (in red) and from a $100 \%$ reduction (zero pesticide, in blue). Losses were estimated using quantile regression for quantile values ranging from 0.1 to 0.9 . Dotted lines indicate $95 \%$ confidence intervals.

reflects situations where pest and disease pressure was high and where pesticide treatments were not able to fully control pests and diseases.

Our results show that the potential grain yield loss caused by a $50 \%$ TFI reduction from current use in winter wheat is limited and is much smaller than the loss attributable to the adoption of a zeropesticide system (0.4-0.9 $\mathrm{tha}^{-1}$ vs. $2-2.3 \mathrm{t} \mathrm{ha}^{-1}$ respectively). These results indicate that the adoption of integrated wheat cropping systems would probably not lead to yield losses exceeding 5 to $13 \%$ of the yield values obtained with the current level of pesticide use. These low yield losses may result from the adaptations of different components of the cropping system, such as the crop sequence, the nitrogen fertilization, and the cultivars. These adaptations could reduce the risks of pest and disease occurrences. However, even with the smallest estimated grain yield loss, a 50\% TFI reduction may not be profitable for farmers. Indeed, a reduction of $50 \%$ of the TFI in France for winter wheat would decrease pesticide costs by about 66 euros per hectare ${ }^{29}$. With current wheat prices of more than $200 €$ per ton ${ }^{35}$, a grain yield loss of $0.4 \mathrm{tha}^{-1}$ due to a $50 \%$ TFI reduction would not be fully compensated by the pesticide cost reduction $(0.4 \mathrm{t}$ ha $^{-1} * 200$ euros $\mathrm{t}^{-1}=80$ euro $\left.^{-1}\right)$. If wheat prices fall below $165 €$ per ton (as in 2010), it would then become profitable for farmers to adopt environmentally-friendly practices decreasing TFI by $50 \%$. This calculation is based on the lowest estimated yield loss of all our estimates. If the highest estimated yield loss is considered $\left(0.9 \mathrm{tha}^{-1}\right)$, the cost of a $50 \%$ reduction in pesticide use will become lower than its benefit only for wheat prices below 74 euros per ton.
Note that these calculations do not take into account the costs induced by possible changes in other cropping practices that may be associated with pesticide use reduction, such as in sowing density, fertilization, or mechanical weeding.

At the scale of the whole country, the yield loss induced by a $50 \%$ decrease in pesticide use would decrease the overall French wheat production by about 2 to 3 millions of tons based on the average of the last five years' wheat acreages ${ }^{1}$. This loss of production would represent about $15 \%$ of the French wheat export, based on production $^{1}$ and export ${ }^{36}$ from 2001 to 2011 . Since the adoption of the environmental policy in 2008 in France, the TFI has slightly decreased in 2011 (TFI $=3.8^{32}$ ). According to our models, this decrease of pesticide use may have generated yield losses ranging from 0.05 to $0.1 \mathrm{t} \mathrm{ha}^{-1}$. These losses are small but may partly explain the yield plateau recently observed in France for wheat ${ }^{37}$. On the other hand, a $50 \%$ reduction of pesticide use would decrease the annual pesticide loss into water, reducing the costs of water purification. The French Ministry of Ecology, Sustainable development, Transport and Housing assessed in 2011 the cost of treating the annual inputs of pesticides to surface and coastal water at between 4 and 15 billion euros ${ }^{38}$. The economic gain may be substantial but is difficult to quantify.

In our study, depending on the estimation method and on the response function, yield losses estimated for zero-pesticide systems varied from 2 to $2.3 \mathrm{tha}^{-1}$. These estimates are higher than the values reported for zero-pesticide systems in Sweden ${ }^{39}$ (from 0.6 to $2.1 \mathrm{t}$ $\mathrm{ha}^{-1}$ ). Yield losses reported in Sweden and Denmark in other

Table 1 | Yield losses resulting from a 50\% reduction of pesticide use (change from TFI 4.1 to TFI 2.05) estimated with two response functions (log and quadratic) and two statistical methods (quantile regression and stochastic frontier). Yield losses are expressed in $\mathrm{tha} \mathrm{h}^{-1}$ and in percentages of the yields obtained with the current level of pesticide use. Results obtained with the quantile regression method are shown for three quantiles (median, and percentiles 20 and $80 \%$ ). 95\% confidence intervals are given in brackets

\begin{tabular}{llcc} 
Function & \multicolumn{1}{c}{ Statistical method } & Yield loss (t ha ${ }^{-1}$ ) & Yield loss (\%) \\
\hline Log & Quantile regression (median) & $0.48(0.26,0.59)$ & $6.74(3.84,8.13)$ \\
Log & Quantile regression (percentile 20\%) & $0.42(0.28,0.68)$ & $6.93(4.7,11.67)$ \\
Log & Quantile regression (percentile 80\%) & $0.43(0.3,0.56)$ & $5.24(3.84,6.85)$ \\
Log & Stochastic frontier & $0.47(0.34,0.61)$ & $5.35(3.9,6.98)$ \\
Quadratic & Quantile regression (median) & $0.88(0.53,1.06)$ & $12.14(7.6,14.28)$ \\
Quadratic & Quantile regression (percentile 20\%) & $0.73(0.49,1.05)$ & $11.96(8.17,16.44)$ \\
Quadratic & Quantile regression (percentile 80\%) & $0.86(0.56,1.03)$ & $10.41(6.98,12.5)$ \\
Quadratic & Stochastic frontier & $0.83(0.61,0.98)$ & $10.18(7.7,12.29)$ \\
\hline
\end{tabular}


Table 2 | Yield losses resulting from zero-pesticide application (change from TFI 4.1 to TFI 0) estimated with two response functions (log and quadratic) and two statistical methods (quantile regression and stochastic frontier). Yield losses are expressed in $\mathrm{tha}^{-1}$ and in percentages of the yields obtained with the current level of pesticide use. Results obtained with the quantile regression method are shown for three quantiles (median, and percentiles 20 and $80 \%$ ). $95 \%$ confidence intervals are given in brackets

\begin{tabular}{ll} 
Function & \multicolumn{1}{c}{ Statistical method } \\
\hline Log & Quantile regression (median) \\
Log & Quantile regression (percentile 20\%) \\
Log & Quantile regression (percentile 80\%) \\
Log & Stochastic frontier \\
Quadratic & Quantile regression (median) \\
Quadratic & Quantile regression (percentile 20\%) \\
Quadratic & Quantile regression (percentile 80\%) \\
Quadratic & Stochastic frontier
\end{tabular}

Yield loss $\left(\mathrm{t} \mathrm{ha}^{-1}\right)$

Yield loss (\%)

$2.31(1.36,2.74)$

$2.02(1.4,2.92)$

$2.13(1.56,2.69)$

$2.33(1.74,2.93)$

$2.23(1.27,2.78)$

$1.84(1.07,2.74)$

$2.1(1.27,2.56)$

$1.98(1.48,2.51)$

$32.26(19.64,37.71)$

$33.04(23.56,49.98)$

$25.97(19.65,32.7)$

$26.43(19.77,33.3)$

$30.79(18.36,36.94)$

$30.04(18.5,42.73)$

$25.5(15.63,30.47)$

$24.31(18.49,31.5)$

studies $^{40,41}$ for zero-pesticide systems were also lower, and ranged from 0.3 to $0.8 \mathrm{t} \mathrm{ha}^{-1}$. The yield losses obtained in our study for zero-pesticide systems correspond to 24.3 to $33 \%$ of the yield estimated with the current pesticide use level. These results are consistent with previous meta-analyses ${ }^{12,13}$ comparing conventional and organic wheat yields (e.g. $27 \%$ and $38 \%$ of estimated yield loss). In these two studies, yield losses were higher for winter wheat than for other major crops (e.g. corn, soybean). It would thus be interesting to apply the methods presented in this paper to other crops, but the amount of yield data included in our database was too limited to do so. With a wheat price of 200 euros per ton, yield losses of zeropesticide systems are not compensated by the benefit resulting from pesticide use reduction, even if the lowest estimated yield loss is considered.

\section{Methods}

Experiments. Experiments located in four sites in France were considered (Supplementary material S1); yields were considered at $0 \%$ of humidity. Each experiment tested several cropping systems, considered here as the treatments, which were replicated two to four times depending on the location (Table 3 ). The number of wheat yield data obtained in a given year is lower than Number of cropping systems * Number of replicates because wheat was not grown every year. Details on cropping systems are given in supplementary materials S3 and S4. Yield was measured on each plot (i.e. replicate) with a combine harvester, with 6 samples per plot (between 0.1 and 0.4 ha in total, depending on the experiment).

The first experiment was located at the INRA Auzeville experimental farm close to Toulouse $\left(43.62^{\circ} \mathrm{N}, 1.45^{\circ} \mathrm{E}\right)$, from 1995 to 2002 , on deep well-drained clay loam soils. The experimental design included 12 plots (about 1.5 ha each). Three different cropping systems (4-year rotations) were randomly allocated to the 12 plots (each cropping system was replicated four times). The three cropping systems were: (1) a "productive yet environmentally-friendly" system, (2) a "technical extensive" system, and (3) a "simple rustic" system. In the first system, maize, soya bean, spring pea and durum wheat or soft wheat were grown, with irrigation when required. In the "technical extensive" system, sorghum, sunflower, winter pea and durum wheat or soft wheat were grown, with lower water and nitrogen inputs. In the "simple rustic" system, the crops were similar to those in the second system, with no irrigation, reduced crop densities and delayed sowing dates ${ }^{16}$. Herbicides and fungicides were systematically applied in all winter wheat plots but at different rates and frequencies depending on the decision rules adopted in each cropping systems. Insecticides were only applied during two years in the "simple rustic" system (see supplementary material S4 for details about pesticide applications).
The second experiment was located at INRA Versailles $\left(48.81^{\circ} \mathrm{N}, 2.14^{\circ} \mathrm{E}\right)$ from 1997 until 2012, on deep loamy well-drained soils. The experimental design included two blocks of eight plots. The plot size was 0.5 ha. Four different cropping systems were tested, and each cropping system was randomly allocated to one plot in each block (each cropping system was replicated four times). The tested cropping systems were: (1) a "highly productive" system, (2) a "low input" system, (3) a "direct seeding mulch-based" system and (4) an organic system. In the "highly productive" system, the crop sequence was oilseed rape -winter wheat- spring pea - winter wheat, with inputs aimed at reaching the potential yield. The "low input" system had the same crop sequence as the first system, but nitrogen fertilization and pesticide use were reduced, as well as mouldboard ploughing frequency (once every two years instead of every year). In the third system, the crop rotation was maize-winter wheat- peawinter wheat. A permanent soil cover was maintained with cash or cover crops. The organic system had a diversified rotation including legumes, with winter wheat every two years. In this system, no mineral fertilizers and pesticides were applied ${ }^{16}$. In the three other systems, fungicides, herbicides and insecticides were applied at different rates in winter wheat plots (See supplementary material S4).

The third experiment has been located at INRA Epoisses near Dijon $\left(47.33^{\circ} \mathrm{N}\right.$, $5.03^{\circ} \mathrm{E}$ ) from 2000 until 2012 , on drained clay soils. The experimental design consisted in two blocks of five plots each. Plot size ranged from 1.1 to 1.7 ha. Five cropping systems were tested and each cropping system was randomly allocated to one plot in each block (each cropping system was replicated two times). The five cropping systems were: (1) a "highly productive" system, (2) an "integrated weed management system with minimum tillage", (3) an "integrated weed management system with no mechanical weeding", (4) an "integrated weed management system with mechanical weeding", and (5) a "zero herbicide" system. In the "highly productive" system, the crop sequence was oilseed rape -winter wheat- winter barley, with chemical weeding. In the second system (minimum tillage), a six-year rotation was used (winter cereals, spring barley, soya bean and oilseed rape), with no mouldboard ploughing and no mechanical tillage. The third system (no mechanical weeding) was similar to the "minimum" tillage system, except that mouldboard ploughing was performed once every two years. In the fourth system (with mechanical weeding), sugar beet was introduced into the rotation; mechanical weeding was used and chemical control was limited as much as possible. The "zero herbicide" system was similar to the previous system except for chemical weed control ${ }^{16}$. Different pesticide applications were used in the five cropping systems (see supplementary material S4)

The fourth experiment has been located at INRA Grignon, close to Paris $\left(48.50^{\circ} \mathrm{N}\right.$, $1.57^{\circ} \mathrm{E}$ ), from 2008 until 2012, on deep loamy well-drained soils. The experimental design included three blocks of 4 plots. The plot size was 0.4 ha. Four cropping systems were tested and each cropping system was randomly allocated to one plot in each block (each cropping system was replicated three times). The cropping systems were: (1) a "productive system with high environmental performance", (2) a "low greenhouse gas emissions" system, (3) a "low energy consumption" system and (4) a "no pesticide" system. In the first system, the crop sequence was winter field beans winter wheat- winter oilseed rape -winter wheat- spring barley, with mustard as a

Table 3 | Main characteristics of the experimental designs

\begin{tabular}{|c|c|c|c|c|}
\hline Site & $\begin{array}{l}\text { Number of cropping } \\
\text { systems }\end{array}$ & $\begin{array}{l}\text { Number of replicates per } \\
\text { cropping system }\end{array}$ & Years with winter wheat (number of yield data per year) & $\begin{array}{l}\text { Number of yield } \\
\text { data per site }\end{array}$ \\
\hline Toulouse & 3 & 4 & 1996 (3); 2000 (1); 2001 (1); 2002 (1) & 6 \\
\hline Versailles & 4 & 4 & $\begin{array}{l}1998(8) ; 1999(8) ; 2000(8) ; 2001(6) ; 2002(8) ; 2003 \\
(8) ; 2004(8) ; 2005(8) ; 2006(8) ; 2007(10) ; 2008(10) ; \\
2009(6) ; 2010(10) ; 2011(6) ; 2012(6)\end{array}$ & 118 \\
\hline Dijon & 5 & 2 & $\begin{array}{l}2001(8) ; 2002(1) ; 2003(5) ; 2004(5) ; 2005(1) ; 2006 \text { (1) } \\
2007 \text { (1); } 2008 \text { (3); } 2009 \text { (4); } 2010 \text { (3); } 2011 \text { (3); } 2012 \\
\text { (5) }\end{array}$ & 40 \\
\hline Grignon & 4 & 3 & $2009(3) ; 2010(6) ; 2011(3)$ & 12 \\
\hline
\end{tabular}


catch crop before the barley. In the second system, the crop sequence was spring field beans - winter oilseed rape- winter wheat- winter barley - maize - triticale. Various species as cover crops were always sown before each spring crop. In the third system, the crop sequence was winter wheat- winter flax - mixed winter wheat and clover spring oats -winter field beans, with clover as a cover crop before oats. In the fourth system, the crop sequence was spring field beans- winter wheat - hemp- triticale maize - winter wheat, with cover crops before hemp and maize. The four cropping systems differed in terms of crop sequence, use of cover crops, soil tillage, weeding methods, fertilization practices, and pesticide use intensity (see supplementary material S4 for details).

Indicator for pesticide use intensity. Only wheat crop was considered in this study. Detailed cropping characteristics of these plots are summarised in Supplementary material S3 to S4. The Treatment Frequency Index ${ }^{21,22}$ was calculated for 176 wheat plots as follows:

$$
\mathrm{TFI}=\sum_{\mathrm{T}} \mathrm{AD}_{\mathrm{T}} / \mathrm{RD}_{\mathrm{T}}
$$

where $\mathrm{T}$ is the index of pesticide product, $\mathrm{AD}$ is the amount applied per hectare and $\mathrm{RD}$ is the recommended amount per hectare. The recommended pesticide rates were extracted from the e-phy database provided by the French Ministry of Agriculture ${ }^{42}$. All pesticide products are considered in this indicator, except for the seed treatments. This indicator is similar to that used in previous studies in Germany ${ }^{43}$ except that ours is calculated for each pesticide product whereas theirs is calculated for each active substance.

Statistical methods. The statistical analysis was carried out with $\mathrm{R}$ software version 3.0-2 (http://www.R-project.org/) using the package quantreg version 5.0-5 (http:// cran.r-project.org/web/packages/quantreg/index.html) and the package frontier version 1.1-0 (http://cran.r-project.org/web/packages/frontier/index.html).

Quantile regression ${ }^{27}$ is a method for estimating functional relations between variables for all portions of a probability distribution. These models are useful when the response variable is affected by more than one factor, when factors vary in their effect on the response, when not all factors are measured, or when the multiple limiting factors interact. Quantile regression was used for estimating the relationship between yield $\mathrm{Y}$ and TFI for all portions of the probability distribution of $Y$. These portions were defined as quantile values. An interesting feature of this approach is that no assumption is required about the probability distribution of the measurements as the function parameters are estimated by a non-parametric technique that consists of minimizing a sum of weighted absolute differences between observations and predictions. The yield was related to TFI using two functions, a log function defined by $\log (\mathrm{Y})=\theta_{0}+\theta_{1} \log (\mathrm{TFI}+0.1)$, and a quadratic function defined by $\mathrm{Y}=$ $\theta_{0}+\theta_{1} \mathrm{TFI}+\theta_{2} \mathrm{TFI}^{2}$ where $\theta_{0}, \theta_{1}$ and $\theta_{2}$ are the parameters of the response functions. The parameters were estimated for several quantiles ranging from 0.1 to 0.9 with a step of 0.1 using the rq function of the quantreg R package.

Stochastic Frontier Analysis was used to estimate a production frontier ${ }^{28}$ relating the maximum yield values that could be reached for a wide range of TFIs. Two types of model were tested. The first one related log-values of yield to $\log$-values of TFI: $\log \left(\mathrm{Y}_{\mathrm{i}}\right)$ $=\theta_{0}+\theta_{1} \log \left(\mathrm{TFI}_{\mathrm{i}}+0.1\right)+\mathrm{v}_{\mathrm{i}}-\mathrm{u}_{\mathrm{i}}$, where $\mathrm{i}$ is the data index, $\mathrm{Y}$ is the grain yield, $\theta_{0}$ and $\theta_{1}$ are the parameters of the response function, $\mathrm{v}_{\mathrm{i}}$ is the stochastic error term and $\mathrm{u}_{\mathrm{i}}$ is the technical inefficiency (effect of limiting factors other than TFI). The second model was defined by $Y_{i}=\theta_{0}+\theta_{1} \mathrm{TFI}+\theta_{2} \mathrm{TFI}^{2}+\mathrm{v}_{\mathrm{i}}-\mathrm{u}_{\mathrm{i}}$, where $\theta_{0}, \theta_{1}$ and $\theta_{2}$ are the parameters of the response function. The error terms $v_{i}$ were assumed identical and independently normally distributed. The inefficiency terms $\mathrm{u}_{\mathrm{i}}$ were assumed to have a half-normal distribution. Parameters were estimated by maximum likelihood using the sfa function of the frontier R package.

We calculated the $95 \%$ confidence intervals by using a bootstrap method ${ }^{44,45}$. Data were sampled with replacement 1,000 times, and the models were fitted to each of the generated samples in turn. The fitted models were used to compute yield losses resulting from a $50 \%$ and $100 \%$ reduction of TFI compared to the reference value of 4.1 .

1. Food and Agriculture Organization of the United Nations (FAOSTAT). FAO Statistical Databases, http://faostat.fao.org/site/567/default.aspx (accessed, October 2013).

2. Foley, J. A. et al. Solutions for a cultivated planet. Nature. 478, 337-342 (2011).

3. Enserink, M., Hines, P. J., Vignieri, S. N., Wigginton, N. S. \& Yeston, J. S. The pesticide paradox. Science. 341, 729 (2013).

4. Elbaz, A. et al. Professional exposure to pesticides and Parkinson disease. Ann Neurol. 66, 494-504 (2009).

5. National Institute of Health and Medical Research in France (Inserm). Pesticides, effets sur la santé. Expertise collective, Synthèse et recommendations. http://www. inserm.fr/actualites/rubriques/actualites-societe/pesticides-effets-sur-la-santeune-expertise-collective-de-l-inserm (accessed, June 2013).

6. Beketov, M. A., Kefford, B. J., Schäfer, R. B. \& Liess, M. Pesticides reduce regional biodiversity of stream invertebrates. PNAS. 110, 11039-11043 (2013).

7. Council Directive 98/83/EC of 3 November 1998 on the quality of water intended for human consumption. Official Journal of the European Communities, L330:32-54 (1998) http://eur-lex.europa.eu/LexUriServ/LexUriServ. do?uri=CELEX:31998L0083:en:NOT (accessed, January 2014).
8. Service of Observation and Statistics in France (SOeS). Les pesticides dans les eaux. http://www.statistiques.developpement-durable.gouv.fr/lessentiel/ar/246/ 211/contamination-globale-cours-deau-pesticides.html (accessed, October 2014)

9. Ecophyto 2018 - Plan ECOPHYTO 2018 de réduction de l'usage des pesticides 2008-2018 (2008) http://agriculture.gouv.fr/IMG/pdf/PLAN_ECOPHYTO_ 2018-2-2.pdf (accessed, January 2014).

10. International Assessment of Agricultural Knowledge (IAASTD). Agriculture at a Crossroads, Synthesis Report (Island Press, 2009); http://www.unep.org/dewa/ agassessment/reports/IAASTD/EN/Agriculture\%20at\%20a\%20Crossroads_ Synthesis\%20Report\%20(English).pdf (accessed, January 2013).

11. Loyce, C. et al. Growing winter wheat cultivars under different management intensities in France: A multicriteria assessment based on economic, energetic and environmental indicators. Field Crop. Res. 125, 167-178 (2012).

12. de Ponti, T., Rijk, B. \& van Ittersum, M. K. The crop yield gap between organic and conventional agriculture. Agr. Syst. 108, 1-9 (2012).

13. Seufert, V., Ramankutty, N. \& Foley, J. A. Comparing the yields of organic and conventional agriculture. Nature. 485, 229-U113 (2012).

14. Food and Agriculture Organization of the United Nations (FAO). World agriculture: towards 2015/2030. An FAO perspective. Earthscan Publications Ltd., London (2003).ftp://ftp.fao.org/docrep/fao/004/y3557e/y3557e.pdf (accessed, October 2014).

15. United Nations, Department of Economic and Social Affairs, Population Division (2013). World Population Prospects: The 2012 Revision, Press Release (13 June 2013): "World Population to reach 9.6 billion by 2050 with most growth in developing regions, especially Africa"http://esa.un.org/wpp/Documentation/pdf/ WPP2012 Press_Release.pdf (accessed, October 2013).

16. Debaeke, P. et al. Iterative design and evaluation of rule-based cropping systems: methodology and case studies. A review. Agron. Sustain. Dev. 29, 73-86 (2009).

17. Kaval, P. The profitability of alternative cropping systems: a review of the literature. J. Sustain. Agr. 23, 47-65 (2004).

18. OECD. Environmental Indicators for Agriculture, Volume 3: Methods and Results. France, Paris (2001). www.oecd.org/tad/sustainable-agriculture/ 40680869.pdf (accessed, October 2013).

19. Pingault, N., Pleyber, E., Champeaux, C., Guichard, L. \& Omon, B. Produits phytosanitaires et protection intégrée des cultures: l'indicateur de fréquence de traitement (IFT), Notes et Etudes Economiques, Ministère de l'agriculture et de la pêche, No 32. (Mars 2009). http://www.agreste.agriculture.gouv.fr/IMG/pdf_ nese090332A3.pdf (accessed, September 2013).

20. Chikowo, R., Faloya, V., Petit, S. \& Munier-Jolain, N. M. Integrated Weed Management systems allow reduced reliance on herbicides and long-term weed control. Agr. Ecosyst. Env. 132, 237-242 (2009).

21. Leroux, P., Albertini, C., Gautier, A., Gredt, M. \& Walker, A. S. Mutations in the CYP51 gene correlated with changes in sensitivity to sterol $14 \alpha$-demethylation inhibitors in field isolates of Mycosphaerella graminicola. Pest Manag. Sci. 63, 688-698 (2007)

22. Leroux, P., Gredt, M., Remuson, F., Micoud, A. \& Walker, A. S. Fungicide resistance status in French populations of the wheat eyespot fungi Oculimacula acuformis and Oculimacula yallundae. Pest Manag. Sci. 69, 15-26 (2013).

23. Prost, L., Makowski, D. \& Jeuffroy, M. H. Comparison of stepwise selection and Bayesian model averaging for yield gap analysis. Ecol. Model. 219, 66-76 (2008).

24. Cade, B. S. \& Noon, B. R. A gentle introduction to quantile regression for ecologists. Front. Ecol. Environ. 1, 412-420 (2003).

25. Cade, B. S., Terrell, J. W. \& Schroeder, R. L. Estimating effects of limiting factors with regression quantiles. Ecology. 80, 311-23 (1999).

26. Cade, B. S., Noon, B. R. \& Flather, C. H. Quantile regression reveals hidden bias and uncertainty in habitat models. Ecology. 86, 786-800 (2005).

27. Koenker, R. \& Bassett, G. Regression quantiles. Econometrica. 46, 33-50 (1978)

28. Battese, E. \& Coelli, T. J. A model for technical inefficiency effects in a stochastic frontier production function for panel data. Empir. Econ. 20, 325-332 (1995).

29. Jacquet, F., Butault, J. P. \& Guichard, L. An economic analysis of reducing pesticides in French field crops. Ecol. Econ. 70, 1638-1648 (2011).

30. French Ministry of Agriculture. Enquête sur les Pratiques Culturales en 2006. http://agreste.agriculture.gouv.fr/page-d-accueil/article/donnees-en-ligne (accessed, October 2013).

31. Köck-Schulmeyer, M. et al. Occurrence and behavior of pesticides in wastewater treatment plants and their environmental impact. Sci. Total Environ. 458-460, 466-476 (2013).

32. French Ministry of Agriculture. Enquête Pratiques culturales 2011 - Les traitements phytosanitaires sur les grandes cultures. Agreste Les Dossiers, $\mathrm{N}^{\circ} 18$ (2013) http://www.agreste.agriculture.gouv.fr/IMG/pdf/dossier18_integral.pdf (accessed, January 2014).

33. Popp, J., Peto, K. \& Nagy, J. Pesticide productivity and food security. A review. Agron. Sustain. Dev. 33, 243-255 (2013).

34. Tiedemann, T. \& Latacz-Lohmann, U. Production risk and technical efficiency in organic and conventional agriculture - the case of arable farms in Germany. J. Agr. Econ. 64, 73-96 (2012).

35. Agreste Conjonture Grandes cultures. Blé et maïs: vers des bilans mondiaux 2013/ 2014 à nouveau excédentaires. Agreste Synthèses - Grandes cultures - Céréales n 2013/213 (2013). http://www.agreste.agriculture.gouv.fr/IMG/pdf/ conjsynt213201307cult.pdf (accessed, October 2013).

36. FranceAgriMer, http://www.franceagrimer.fr/filiere-grandes-cultures/Cereales (accessed, October 2013). 
37. Michel, L. \& Makowski, D. Comparison of Statistical Models for Analysing Wheat Yield Time Series. Plos One 8, e78615 (2013).

38. Bommelaer, O. \& Devaux, F. Etudes \& documents - Coûts des principales pollutions agricoles de l'eau. Ministère de l'Ecologie, du Développement durable, des Transports et du Logement, Service de l'économie, de l'évaluation et de l'intégration du développement durable. Economie et évaluation ${ }^{\circ} 52,34 \mathrm{p}$ (2011). http://www.developpement-durable.gouv.fr/IMG/pdf/ED52-2.pdf (accessed, September 2013)

39. Delin, S. et al. Impact of crop protection on nitrogen utilization and losses in winter wheat production. Eur. J. Agron. 28, 361-370 (2008)

40. Kristensen, K. \& Ericson, L. Importance of growth characteristics for yield of barley in different growing systems: will growth characteristics describe yield differently in different growing systems? Euphytica. 163, 367-380 (2008).

41. Wiik, L. Yield and disease control in winter wheat in southern Sweden during 1977-2005. Crop Prot. 28, 82-89 (2009).

42. Ephy website. Le catalogue des produits phytopharmaceutiques et de leurs usages des matières fertilisantes et des supports de culture homologués en France. French Ministry of Agriculture and Agribusiness.http://e-phy.agriculture.gouv.fr/ (accessed, October 2013)

43. Sattler, C., Kachele, H. \& Verch, G. Assessing the intensity of pesticide use in agriculture. Agr. Ecosyst. Environ. 119, 299-304 (2007).

44. Efron, B. \& Tibshirani, R. Bootstrap methods for standard errors, confidence intervals and other measures of statistical accuracy. Stat. Sci. 1, 54-75 (1986).
45. Efron, B. \& Tibshirani, R. An Introduction to the Bootstrap (Chapman \& Hall, London 1993).

\section{Author contributions}

D.M., L.H., G.R. and M.-H.J. designed research; M.-H.J., M.B., C.C.-D., P.D. and N.M.-J. designed experiments; A.P. and L.H. built the database; L.H. and D.M. analysed data and wrote the paper. All authors reviewed the manuscript.

\section{Additional information}

Supplementary information accompanies this paper at http://www.nature.com/ scientificreports

Competing financial interests: The authors declare no competing financial interests. How to cite this article: Hossard, L. et al. Effects of halving pesticide use on wheat production. Sci. Rep. 4, 4405; DOI:10.1038/srep04405 (2014).

(c) $($ ) $\odot$ This work is licensed under a Creative Commons AttributionNonCommercial-NoDerivs 3.0 Unported license. To view a copy of this license, visit http://creativecommons.org/licenses/by-nc-nd/3.0 